\title{
MAPAS, ONTOLOGIAS E BPM PARA MODELAGEM E ANÁLISE DO FLUXO DE INFORMAÇÃO: Jornal laboratório
}

MAPS, AND ONTOLOGIES BPM FOR MODELING AND ANALYSIS OF FLOW INFORMATION: laboratory journal

MAPAS, ONTOLOGÍAS Y BPM PARA MODELADO Y ANÁLISIS DEL FLUJO DE INFORMACIÓN: Jornal Laboratório

\section{Benedito Medeiros Neto}

Pos-Doutorado/Informática: FrameWork Semântico para Jornalismo pelo CIC/IE/UnB (2018). PósDoutorado: Literacy digital e mobile learning pela Escola de Comunicação e Arte/USP (2014). Professor FACIUnB e CIC\UnB. medeirosneto@unb.br

0000-0001-9562-1587

\section{Thallita Alves Silva}

Jornalista pela Universidade de Brasília (UnB). Workflow para auxiliar na modelagem de processos de produção de notícia em jornal laboratório. E-mail: thallitaessi@gmail.com.
Recebido em: 16.02.2021.

Aceito em: 16.04.2021.

Publicado em: 01.07.2021.

\begin{abstract}
RESUMO
Esta pesquisa mostra modelagem do workflow de um jornal universitário com base em mapas mentais e conceituais e propõe uma ontologia de domínio. 0 estudo foi realizado com base em conceitos, como jornalismo multiplataforma, web jornalismo e uso de TIC. Em termos metodológicos, trata-se de um estudo de caso, combinado com observação de participantes por meio de entrevistas semiestruturadas. Como parte da modelagem, elaborou-se um mapa mental do fluxo de trabalho do Campus. Depois o processo foi aprimorado para um mapa conceitual e por último chegou-se a uma ontologia. Os resultados mostram a possibilidade de se compreender o processo de um jornal de forma visual, compartilhá-lo ou extrapolá-lo e aplicá-lo em outras redações, e, ainda, aprimorar o fluxo de trabalho com apoio do mapa de gestão de processos (BPM).
\end{abstract}

PALAVRAS-CHAVES: workflow; jornalismo multiplataforma; jornal-experimental; mapa mental e conceitual; ontologia.

\section{Introdução}

O jornalismo que compartilha sua matéria prima, a informação, pelo uso e mediação das tecnologias, não é uma exceção, e deverá tirar vantagem do uso das Tecnologias da Informação e Comunicação - TIC, notadamente de algoritmos, automação dos processos de coleta, avaliação, composição, apresentação e de distribuiçã̃o de notícias. Portanto, os tradicionais meios de comunicação do século passado, e mesmo os mais recentes surgidos nestas duas últimas décadas buscam reorganizar seus modelos de gestão de negócio para manter-se no mercado. 
As TIC, propulsoras de una revolução que continua em atividade, transformando organizações e os negócios nos principais setores da sociedade, de forma direta ou indireta, impactaram fundamentos ou obtiveram excelentes resultados. Isto hoje acontece nos processos de produção na agricultura, indústria, comércio, serviços e governo. $O$ Jornalismo atual ainda faz um médio acesso das informações de agregadores, mídia social e de dados abertos (BERVEN et al, 2020).

Os profissionais que lidam com comunicação, notícias e informação enfrentam todos os dias desafios, seja o volume de dados e informações, sejam as novas formas de produção ou a adequação no tratamento e distribuição de notícias. Eles entendem, ainda, que as informações e sua distribuição, se possível em tempo real, estão sendo criadas e pensadas de forma a chegar mais perto dos leitores em todo o planeta, e que isto é, mais do que uma simples conexão em rede. A somatória de equipamentos em data center permite mais big data na nuvem a cada mês, e tanto mais poderosos quanto mais acessíveis.

Observa-se um aumento de redes de telecomunicações, seja por fibra, microondas, paralelo à profusão de aplicativos (APP) para celulares, e com as dinâmicas redes sociais, fortemente impactadas pela era de dados e informação, e do jornalismo de dados. Essa expansão favorece as condições necessárias para um ambiente de inovações e rupturas em diversos níveis do processo de fazer jornalismo (DEUZE; WITSCHGE, 2018).

O consumo de informações sofreu grandes mudanças com o advento da Internet 1, 2 e 3, e a evolução de novas tecnologias digitais, como as aplicações das TIC, robôs e automatizações de processos. O acesso da população brasileira ao uso de internet já alcança 134 milhões de usuários, segundo a Pesquisa TIC Domicílios 2019, (Cetic.br), vinculada ao Comitê Gestor da Internet no Brasil e representa 74\% da população com 10 anos ou mais. Portanto, para planejar e organizar a produção de conteúdos faz-se necessário lançar mão de procedimentos e ferramentas não convencionais, que a Internet 3.0, incorpora às tecnologias de Web Semântica.

Os formatos de comunicação e o consumo de conteúdo foram transformados pelas novas tecnologias. Nesse cenário, o jornalismo tem sido impactado e seus processos repensados dada a presença marcante das tecnologias, e o surgimento de novos canais de comunicação. Adiciona-se a necessidade de adaptação da linguagem dos profissionais para acompanhar as demandas e ocupar os espaços de interação e informação com o público. Os locais de presença jornalística estão sendo expandidos bem como o estão as ferramentas úteis no trabalho. Os processos de produção podem contar com as TICs, como por exemplo, o que vamos tratar aqui nesta pesquisa no qual 
se apresenta um desenho do workflow do fluxo de produção de um jornal, Campus Online (BARCELLOS; SILVA, 2019).

Nos processos de produção de conteúdo em redações (workflow) de jornais nacionais e internacionais, deve-se, numa etapa de planejamento, estudar e identificar as tecnologias para apoio às equipes, iniciando-se pelo desenho do workflow (rotinas produtivas) da redação e definição de ferramentas de TI como suporte. Também devem fazer parte do escopo da redação convergente a implementação de sistemas colaborativos, presença em redes sociais, aprendizagem colaborativa com suporte computacional, padrões de informação, modelos de gerenciamento de mídias digitais e aperfeiçoamento dos CMS -Content Management System (JORGE et al, 2016).

Neste contexto de transformação que passam a maioria das organizações não só jornalísticas, destacam-se dois pontos. O primeiro é que a convergência digital ganha cada vez mais força. Por isso, se faz necessário pensar novas formas para melhorar o desempenho do trabalho jornalístico. Uma forma de preparo para esse cenário de jornalismo convergente, os ambientes de redação virtual e produção multimídia são as cadeias de ensino, na figura dos jornais-laboratórios, que exercem papel crucial para a construção profissional e aproximação dos discentes com a realidade do mercado de trabalho (JORGE et al, 2016).

O segundo ponto tem a ver com a inquestionável transformação digital que passam todas as organizações. Seus gestores são permanentemente cobrados para apresentarem novos modelos gerenciais e de negócios, com base em inovação, pois considera-se que os atuais modelos em vigor não conseguem responder aos desafios do mercado, justificado que as práticas organizacionais dentro das redações e nas relações com os clientes, com as empresas de comunicação e com seus consumidores não são suficientemente flexíveis. $E$, portanto, não são apropriadas para a realidade em que as empresas de mídia atualmente operam e exploram (SANTOS et al, 2019).

Dado esse contexto, esta pesquisa propõe descrever o contexto e estudar o caso do jornal-laboratório Campus Multiplataforma1. Isso envolve o mapeamento de workflow e a construção de uma ontologia para a modelagem e análise de processos, documentação e implementações tecnológicas que levam ao aprimoramento e continuidade de pesquisas de inovação para o âmbito de ensino e a prática do jornalismo em universidades e, futuramente, em empresas do setor (FONSECA et al, 2018)

Os objetivos desta pesquisa podem ser resumidos como:

\footnotetext{
${ }^{1}$ http://app.campus.fac.unb.br A versão online do jornal Campus foi criada em 2007 e é disciplina do $5^{\circ}$ semestre do curso de Jornalismo da UnB. Com um jornalismo multiplataforma, o Campus Online compartilha informações sobre tudo o que acontece na Universidade de Brasília.
} 
a) Elaborar os mapas mentais e mapas conceituais do processo de produção do jornal-laboratório Campus Multiplataforma2;

Outro ponto que se faz útil nesta análise e que está presente tanto na ideia de ausências da $A C$ quanto na $A D$ é a observação daquilo que é excluído do texto ou do discurso visual, assumindo-se que aquilo que deixa de ser dito também possui significado. Segundo Van Djik (2005, p. 44), quando é possível demonstrar que a informação omitida por um discurso faz parte do modelo mental proposto por ele ou pelo conhecimento geral partilhado sobre aquele assunto, esta omissão passa a ser também uma propriedade relevante do discurso e deve ser observada pelo analista.

Finalmente, seja por um viés de $A C$ ou de $A D$, fica mais do que clara a importância de não ficarmos sujeitos à linguagem e às mensagens a que estamos expostos, mas sim nos posicionarmos criticamente no processo de comunicação.

\section{Web semântica e um estudo de caso e observação do Campus Multiplataforma}

Apesar de os próprios jornalistas reconhecerem que muitas vezes eles podem ser bastante resistentes à mudança, e a implementação de tecnologias da informação, tais como aplicativos (APP) e sistemas da informação, isso sempre foi algo que thes tem preocupado. Mas ao mesmo tempo, esse quadro ou situação pode indicar uma sensação geral de otimismo quando os profissionais são incentivados a se envolverem com novas tecnologias e novos formatos, o que requer uma nova postura dos gestores das redações e componentes de cada editoria (SANTOS et al, 2019).

O fato é que todos os jornais da América do Sul e Central têm buscado modelos de negócios viáveis e a adoção de workflows eficientes para suas redações, já que a receita de produtos e serviços digitais não é suficiente para suportar os custos operacionais de uma empresa jornalística, que atualmente opera com uma proporção de 1:10. Mesmo com as facilidades que as novas tecnologias oferecem (que se tornam mais acessíveis a cada dia), a produção de conteúdo para jornalismo de dados, jornalismo de texto e jornalismo de áudio e vídeo ainda é cara (JORGE; MEDEIROS NETO, 2021).

Neste cenário desfavorável para organizações jornalísticas, deve-se considerar o impacto tecnológico, e a necessidade de adaptação dos jornalistas ao trabalho plenamente inserido no ciberespaço, sendo, portanto, fundamental acompanhar os novos rumos para a Web nesta década. Nesse sentido, vemos o conceito e aplicação da

2 SILVA, T. A. Workflow para auxiliar na modelagem de processos de produção de notícia em jornal laboratório. TCC apresentado à Faculdade de Comunicação da Universidade de Brasília, Brasília, DF. 2019 
Web Semântica (3.0), que está diretamente ligado ao formato dos conteúdos na Web e ao tipo de material que deve ser produzido para o ambiente online, e para o uso de procedimentos com base em suas tecnologias (BERNERS-LEE; HENDLER; LASSILA, 2001).

O conceito de Web Semântica apareceu com Tim Berners-Lee, James Hendler e Ora Lassila (EBERTZ, 2013) em um artigo publicado na Scientific American. The semantic Web: a new form of Web content that is meaningful to computers will unleash a revolution of new possibilities foi o nome dado ao artigo de 2001, que abriu caminho para novas reflexões e contribuições para o termo.

A Web atual ou Web sintática (BREITMAN, 2005) é desenvolvida em linguagem natural, seguindo a orientação da nossa linguagem materna. Ela é composta de hipertextos, os quais o computador não interpreta, apenas apresenta para os usuários. Enquanto a Web Semântica é composta de ferramentas e agentes, a Web Services, apresenta modelos semânticos, metadados, ontologias e linguagem estruturada apropriada à Web.

O uso das Ontologias de conteúdos e da Web Semântica no jornalismo pelos jornalistas é uma realidade nos dias de hoje. De fato, antes mesmo das tentativas de uso de tecnologias semânticas, os jornais já haviam feito investimentos significativos em seus sistemas de gerenciamento de notícias e empreendido esforços consideráveis de padronização para facilitar a interoperabilidade (TRONCY, 2008). Desde um estágio inicial, a pesquisa explorou uma orientação semântica na produção jornalística (por exemplo, o uso de metalinguagem, ontologia e tecnologias da Web Semântica) e como elas podem apoiar o desenvolvimento de sistemas colaborativos que suportam as funções de produção dentro da escrita jornalística (MEDEIROS NETO et al 2019).

Uma das principais diferenças que podemos notar da Web 2.0 para 3.0 é nos momentos de busca, pois o fato de os conceitos não estarem estruturados e correlacionados gera um número muito grande de resultados e, em muitos casos, com assuntos fora de contexto por conta da baixa precisão. A Web Semântica oferece recursos técnicos que tornam as ações de publicação e recuperação nos novos canais da Internet. E o uso de sistemas de gerenciamento de conteúdo (CMS) mais inteligentes e pragmáticos traz "possibilidades de identificação de significados e de geração de inferências, e têm o potencial de maximizar a automatização nos processos realizados pelas máquinas" (LEL; MIELNICZUK, 2012).

Com base nos conceitos vistos e facilidades já disponíveis, a Web Semântica possibilita uma organização maior das informações na rede, permite que o conteúdo disponibilizado em portais seja compreendido e interpretado por computadores (BREITMAN, 2005) e isso pode significar mais conexões de conteúdo, resultados de busca 
mais precisos e economia de tempo para os ambientes de trabalho compartilhado, como as redações virtuais.

Tim Berners-Lee (2001) sugeriu um modelo em camadas para a estruturação da Web do futuro que foi popularizado como "bolo de noiva". Esse modelo está organizado em uma construção de camadas, que evolui a cada etapa. A proposta pode ser vista na APÊNDICE1: Figura 1, como uma das visões da Web Semântica pelo o Consórcio W3C (World Wide Web Consortium).

Entre a diversidade de elementos que compõem a Web Semântica está a ontologia, que é a conceitualização de termos: a elaboração de vocabulário próprio de uma área de conhecimento. Neste trabalho, as ontologias são fundamentais para a construção de vocabulários próprios de uma redação, que poderão ser usados em anotações semânticas, acessados e processados automaticamente (PATEL-SCHNEIDER, 2001 apud CHAVES, 2015, p. 47).

Ontologias, conteúdos e Web Semântica são assuntos que trabalham juntos há um bom tempo. Desde um estágio inicial, a pesquisa explorou uma orientação semântica na produção jornalística (por exemplo, o uso de metalinguagem, ontologia e tecnologias da Web Semântica) e como elas podem apoiar o desenvolvimento de sistemas colaborativos que suportam as funções de produção dentro da escrita jornalística e distribuição por canais de comunicação.

De fato, antes mesmo das tentativas de uso de tecnologias semânticas, os jornais já haviam feito investimentos significativos em seus sistemas de gerenciamento de notícias (CMS), e empreendido esforços consideráveis de padronização para facilitar a interoperabilidade de seus conteúdos (TRONCY, 2008).

Considerando a estruturação da Web Semântica e a metodologia do estudo de caso, em tela, levanta-se os dados e informações do processo de produção por meio de observações diretas e entrevistas sistemáticas e também em arquivos disponíveis do Campus Multiplataforma para esta pesquisa.

No caso do Campus Multiplataforma, foram analisados os projetos que retratam a linha editorial, propostas e decisões assumidas pelas turmas da disciplina "Campus Multimídia" do Departamento de Jornalismo/FAC/UnB de 2017 e 2018 e, para aprimorar a compreensão dos processos, a turma de 1/2019 foi acompanhada por meio de observação de algumas das aulas e entrevistas com os alunos tomadores de decisão (BARCELOS; GIL, 2018).

A compreensão do Campus e a coleta de dados e informações contou com o processo empírico qualitativo, no qual foi possível: (a) identificar as alterações e adequações implementadas a cada turma do jornal-laboratório, (b) descrever as 
mudanças, (c) mapear a relação de alunos com a quantidade de repórteres e editores, e (d) identificar as plataformas e narrativas. Esse processo viabiliza desde o inicio da pesquisa, a compreensão mais detalhada e aprofundada do trabalho no jornal Campus Multiplataforma (MOLINA: MEDEIROS NETO, 2017). Para tal compreensão, foi observado:
a. Definição das plataformas de trabalho;
b. Narrativas jornalísticas utilizadas;
c. Discussão de pauta;
d. Distribuição de tarefas;
e. Distribuição nas plataformas;
f. Composição dos grupos de trabalho; e
g. Análise da repercussão do conteúdo

O modelo de workflow do Campus apresentado aqui foi construído com base no levantamento de dados e informações disponíveis para os estudantes e na observação participante. Uma vez desenvolvido o mapa mental3 como base início da elaboração do workflow do Campus, foram realizadas as entrevistas para a validação do fluxo de trabalho (Vide Quadro 1).

Quadro 1 - Utilização de plataformas no Campus

\begin{tabular}{|l|c|l|l|l|l|}
\hline Plataformas & $1 / 2017$ & $2 / 2017$ & $1 / 2018$ & $2 / 2018$ & $1 / 2019$ \\
\hline Aplicativo & Não & Não & Desenvolvimento & Sim & Sim \\
\hline Facebook & $\operatorname{Sim}$ & $\operatorname{Sim}$ & $\operatorname{Sim}$ & $\operatorname{Sim}$ & Sim \\
\hline Instagram & $\operatorname{Sim}$ & $\operatorname{Sim}$ & $\operatorname{Sim}$ & $\operatorname{Sim}$ & Sim \\
\hline Site & $\operatorname{Sim}$ & $\operatorname{Sim}$ & $\operatorname{Sim}$ & $\operatorname{Sim}$ & Sim \\
\hline Twitter & $\operatorname{Sim}$ & $\operatorname{Sim}$ & $\operatorname{Sim}$ & $\operatorname{Sim}$ & $\operatorname{Sim}$ \\
\hline
\end{tabular}

\footnotetext{
3 MAPA MENTAL é uma pequena técnica de organização do pensamento que pode ser utilizado para estudar, para planejar um trabalho ou qualquer outro tipo de projeto: http://www.filosofiacienciaarte.org/attachments/article/992/Mapa\%20MENTAL\%20V43\%20\%202016-17-18-2019.pdf.
} 


\begin{tabular}{|l|c|c|c|l|l|} 
WhatsApp & Não & Não & Não & Sim & Sim \\
\hline YouTube & $\begin{array}{c}\text { Sim } \\
\text { (repositório) }\end{array}$ & $\begin{array}{c}\text { Sim } \\
\text { (repositório) }\end{array}$ & Desenvolvimento & Parado & Sim \\
\hline
\end{tabular}

Fonte: SILVA, 2019, p.57

A observação participante foi realizada no segundo semestre de 2018 e no primeiro semestre de 2019, em doze aulas ao todo da disciplina Campus Multimídia, com anotações sobre: as principais conversas da turma, do comportamento dos alunos, comprometimento, participação e contribuição para tomada de decisões, acompanhamento da distribuição de pauta por repórteres e definições do prazo de entrega. Ao observar a produção do jornal-laboratório, estrutura-se a mesma em um quadro com a presença digital e editorial em diferentes plataformas ao longo dos semestres analisados (SILVA, 2019).

Uma vez compreendidas as plataformas de atuação, seguiu-se para compreender a composição de atores do jornal (Vide APÊNDICE 2: Figura 2).

E a partir desses dois cenários deu-se início à elaboração do workflow em forma de mapa mental, que aprimoramos para um mapa conceitual4 e evoluímos a uma ontologia como será apresentado no próximo item

\section{Processos e workflow do Campus}

Na primeira década deste século, os processos de fluxo de trabalho de notícias existentes eram pouco vistos como workflow. Na opinião de TRONCY (2008) os itens de notícias são tipicamente: i) produzidos por agências de notícias, jornalistas independentes ou mídia cidadã; ii) os seus conteúdos são aprimorados por jornais, revistas ou emissoras e finalmente; e iii) entregues aos usuários finais por meio dos respectivos canais. Os itens de notícias normalmente quando acompanhados por um conjunto de metadados5 e descrições facilitam seu armazenamento e a sua recuperação.

4 MAPAS CONCEITUAIS são ferramentas gráficas (diagramas indicando relações entre conceitos/palavras) para organização e representação do conhecimento. Não devem ser confundidos com organogramas ou diagramas de fluxo, pois não implicam sequência, temporalidade ou direcionalidade. http://www.filosofiacienciaarte.org/index.php/comunicacaoinformacao-computacao/1004-modulo-ix-mapas-conceituais-2

${ }^{5}$ Metadados, ou Metainformação, são dados sobre outros dados. Um item de um metadado pode dizer do que se trata aquele dado, geralmente uma informação inteligível por um computador. Os metadados facilitam o entendimento dos relacionamentos e a utilidade das informações dos 
No entanto. no início, muitos dos metadados eram perdidos devido a problemas de interoperabilidade de ambientes, que ocorrem ao longo do fluxo de trabalho, algo que está mudando com o uso de big datas e tecnologias da Web Semântica, inclusive no Brasil. Além disso, na interface do usuário final, muitas vezes as oportunidades de fazer uso dos metadados disponíveis são perdidas, ainda. Consequentemente, os leitores e usuários são forçados a explorar informações de notícias em ambientes que contêm grandes quantidades de informações irrelevantes, não confiáveis e repetidas, e agora com a presença de fakenews, o que se soma ao acesso insuficiente ao conhecimento prévio (TRONCY, 2008)

A representação dos processos de produção e fluxo de trabalho do jornal Campus compreendeu a leitura e observação direta durante a disciplina Campus Multimídia (2018 e 2019). E o uso das melhores práticas e tecnologias para representar o workflow, foi alcançado pelo uso de duas ferramentas: mapa mental e mapa conceitual que que são detalhas a seguir.

A disciplina Campus Multimídia, do curso de jornalismo da Faculdade de Comunicação da UnB, analisa o impacto das inovações tecnológicas na transformação do jornalismo (a própria invenção da prensa de tipos móveis, um marco emblemático), que resultam em novos formatos de apresentação e/ou em novas plataformas. Assim, inaugurou-se, no primeiro semestre de 2017, um trabalho coletivo, construído por alunos coordenados por um professor (BARCELLOS; SILVA, 2020).

O desenvolvimento do Projeto e processo de desenvolvimento coletivo de veículo jornalístico digital multiplataforma, a cada semestre, norteiam um processo didático de criação de um veículo jornalístico multiplataforma, totalmente alocado na web, tendo como plataformas alguns canais dentre as chamadas redes sociais, Twitter,

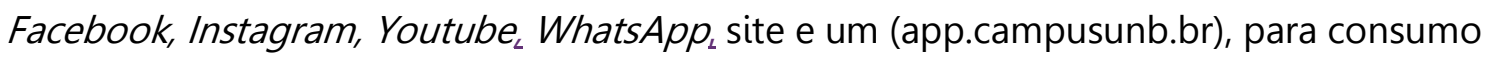
preferencial pelo smartphone (BARCELLOS; GIL, 2018).

\subsection{O mapa mental do Campus}

O mapa mental foi utilizado como uma primeira forma de visualização e entendimento do workflow do Campus em busca de um registro visualmente intuitivo sobre o processo. De acordo com Buzan (2016), o criador da técnica, mapas mentais são maneiras de registrar informações. Eles permitem transmitir aquilo que está na mente, organizar os pensamentos e expandir a compreensão.

dados. Metadados são indispensáveis para a comunicação entre computadores, mas podem ser inteligíveis também por humanos. Vide Wikipídia, https://pt.wikipedia.org/wiki/Metadados 
Ao longo dos dois anos e meio de trabalho, houve várias mudanças e adaptações próprias de cada turma. As principais contribuições foram: inclusão de novas plataformas, como Aplicativo Campus (DE SOUSA; BARCELLOS, 2019), WhatsApp, YouTube, inclusão de narrativas, por exemplo, podcast, textos de acessibilidade; e outras mudanças com característica mais gerencial como a distribuição dos repórteres de acordo com as demandas de pauta e não apenas por plataformas (SILVA, 2019).

Considerando a flexibilidade da equipe, os processos, linha editorial e fluxo de trabalho, foi elaborado um workflow para demonstrar as etapas de produção da redação do Campus Multiplataforma. Vide APÊNDICE 3: Figura 3 - Mapa mental em visualização cronológica. Fonte: SILVA, 2019, p.69.

O mapa mental da Figura 3 (APÊNDICE 3) foi apresentado ao Conselho Editorial do Campus Multimídia e validado, em 2019. Na sequência, teremos o Mapa Conceitual e a Ontologia do Campus criados com base nos projetos da disciplina, observação da turma e validação presencial do mapa mental (SILVA, 2019).

A identificação do Conselho Editorial, ou de, ao menos, um dos membros pode ser percebida pelo losango laranja ao longo do processo. A representação das plataformas também possui o mesmo formato para marcar que todos possuem a mesma relevância e não exercem hierarquia ou subordinação entre si (BARCELLOS; SILVA, 2020).

Para a elaboração, consideramos o processo de pré-pauta do jornalismo feito em sua maioria pela Radioescuta que, neste semestre, foi realizada pelos próprios editores e apresentada ao Conselho Editorial para discussão e decisão sobre a continuidade ou não da pauta.

Com a aprovação do Conselho Editorial, as pautas serão direcionadas para as devidas plataformas, com as narrativas jornalísticas e repórteres já definidos. Na fase de apuração, serão realizadas as entrevistas, captação de imagens, vídeos e conteúdo para a construção da matéria. Em seguida, a matéria passa para a etapa de revisão sob responsabilidade do editor-chefe de cada plataforma.

A equipe de arte tem presença constante na definição dos melhores formatos e linguagem visual para divulgação do conteúdo. O editor-chefe de cada plataforma, em parceria com os repórteres, distribui o conteúdo como planejado e cada editor tem a função de capturar as métricas e compartilhar com toda a equipe os resultados. Os dados captados são importantes para o ciclo de decisões do Conselho, sejam sobre horários de publicação, narrativas ou plataformas. Esse processo pode acontecer simultaneamente, em um ambiente virtual, com diferentes pautas, para uma só ou múltiplas plataformas. 


\subsection{Do Conselho Editorial ao Mapa Conceitual do Campus}

Com o Mapa Mental elaborado, ajustado pelas observações da turma 1/2019 do Campus Multiplataforma e validado pelo Conselho Editorial, o Mapa Conceitual pode ser construído. Para a elaboração do Mapa Conceitual, consideramos as equipes, plataformas, tipos de narrativa utilizadas e os processos de trabalho da redação.

A decisão de fazer um Mapa Conceitual do workflow do Campus surgiu pelo entendimento de que essa é uma forma prática para descrever e transmitir as conexões entre as equipes do jornal-laboratório e evoluir rumo ao desenvolvimento da Ontologia do Campus. De acordo com Moreira e Buchweitz (1993), a técnica de mapa conceitual é flexível e pode ser usada para diferentes situações e finalidades.

O Mapa Conceitual foi desenvolvido no software CmapTools uma ferramenta do Institute for Human and Machine Cognition (IHMC) na Florida. A solução tecnológica foi criada justamente para incentivar o conhecimento, permitir a representação de dados por meio de mapas, estabelecer conexões e relacionar termos de forma individual ou coletiva (SILVA, 2019). Considerando a flexibilidade de conexão e a melhor organização por meio do mapa conceitual elaboramos o mapa representado na Figura 4. Vide o APÊNDICE 4: Figura 4 - Mapa Conceitual do Campus Multiplataforma. Fonte: SILVA, 2019, p.73.

O mapa conceitual foi desenvolvido no software CmapTools ${ }^{6}$ uma ferramenta do Institute for Human and Machine Cognition (IHMC) na Florida. A solução tecnológica foi criada justamente para incentivar o conhecimento, permitir a representação de dados por meio de mapas, estabelecer conexões e relacionar termos de forma individual ou coletiva. Considerando a flexibilidade de conexão e a melhor organização por meio do mapa conceitual elaboramos o mapa representado na Figura 4 no APÊNDICE 4:

\section{A modelagem da Ontologia de Domínio do Campus Multiplataforma}

Vive-se em contexto "hiper conectado" e com a presença marcante das tecnologias da informação e comunicação - TICs em quase todos os setores da sociedade, e espera-se que os jornalistas aprimorem suas habilidades no uso de ferramentas, bem como suas práticas e rotinas de trabalho com uso ou suporte das TICs.

6 The IHMC CmapTools software empowers users to construct, navigate, share and criticize knowledge models represented as concept maps. Vide http://www.filosofiacienciaarte.org/index.php/comunicacao-informacao-computacao/992modulo-iv-mapa-mental 
Podendo usar sistemas de informação, aplicativos, e até agentes inteligentes e robôs, e isto os liberam do trabalho em rotinas, muitas vezes repetitivo, sem a necessidade de nenhuma supervisão direta. Ao fazê-lo, eles se deslocam de maneira vulnerável dentro e fora de redações grandes e pequenas e organizações de notícias, tentando fazer a diferença e sobreviver em um mercado extremamente competitivo. Para fazer frente a este desafio é necessário intensificar seus conhecimentos e habilidades em tecnologia (DEUZE; WITSCHGE, 2018).

Dentro da diversidade de tecnologias, possibilidades e métodos de abordagem da Web Semântica ou Internet 3.0 destaca-se as Ontologias. Elas já estão consolidadas na Ciência da Computação, e mais recentemente, já se fazem presentes na Ciência da Informação e na Comunicação em muitos países da Europa, Américas e Ásia. Ontologia é um termo originário da filosofia, que está ligado ao "ramo da metafísica que estuda os tipos de coisas que existem no mundo". A grafia deriva do grego ontos, ser, e logos, palavra. Sua origem remete ao vocábulo categoria, que diz respeito à classificação de espécies e coisas (ALMEIDA, 2003 apud MORAIS; AMBROSIO, 2007, p. 2). Segundo LAMMEL e MIELNICZUK (2012):

As ontologias oferecem um modelo lógico de relacionamentos entre conceitos, como em uma taxonomia, e, além disso, institui regras de relacionamentos entre estes conceitos, tais como pertencimento, igualdade ou distinção. As ontologias possibilitam uma maior automatização no tratamento de dados, pois as inferências dão autonomia às máquinas.

Para dar continuidade ao estudo de métodos e procedimentos para modelagem do processo de produção, deve-se compreender o conceito de ontologia ${ }^{7}$, para daí desenvolver a ontologia do Campus, e elaborar uma representação do workflow do jornal de maneira estruturada, organizada e conceituada. Faz-se necessário, ainda, conhecer as bases da ontologia e suas ferramentas/softwares como o Protégé(FONSECA et al, 2018).

\footnotetext{
${ }^{7}$ As ontologias oferecem um modelo lógico de relacionamentos entre conceitos, como em uma taxonomia, e, além disso, institui regras de relacionamentos entre estes conceitos, tais como pertencimento, igualdade ou distinção. As ontologias possibilitam uma maior automatização no tratamento de dados, pois as inferências dão autonomia às máquinas. Vide http://www.filosofiacienciaarte.org/index.php/curso-programacao-python/1005-modulo-ixmapas-conceituais-3
} 
O desenvolvimento da modelagem do fluxo de produção do Jornal Experimental, com base em ontologia seguiu, em primeiro lugar, com a representação do fluxo de trabalho pelo seu Mapa Mental. Depois com a descrição das classes, e com as relações entre classes e aperfeiçoamento da representação chegou-se ao Mapa Conceitual. Deste modo, foi possível categorizar as classes, suas propriedades e relações no domínio da redação universitária, passo importante para construção da sua ontologia (ISHIKAWA; MEDEIROS NETO, 2019).

A modelagem da ontologia de domínio do Campus Multimídia iniciou, de fato, após a determinação dos papéis dos atores dentro da redação jornal experimental. Em seguida, colocou-se a modelagem da ontologia no Protégé de acordo com os papéis e tarefas no processo de produção da notícia nas Figuras 3 e 4.

A criação da ontologia se dá pelos passos seguintes: hierarquia de classes, hierarquia de objetos (predicados), atributos da classe e indivíduos das classes. A hierarquia de classes da ontologia se encontra de acordo com a Figura 4. As classes que não se associam são modeladas como disjuntas (ex: pessoa e material). A Figura 5 representa a modelagem dos objetos de acordo com as tarefas presentes no processo. Para atender a busca semântica de forma mais generalizada, modelamos os indivíduos repórter, instância da classe Repórter e editor, instância da classe Editor-Chefe.

Para o desenvolvimento das ontologias, os estudantes da disciplina de Tópicos Especiais em Comunicação 1: Ontologia ${ }^{8}$ na Internet ofertada na FAC/UnB dedicaram quase um semestre. Os estudantes ${ }^{9}$ foram convidados para trabalhar em uma equipe de projeto para elaborarem a ontologia do Campus como trabalho final da disciplina. Para isso eles realizaram as seguintes tarefas:

- Estudo e levantamento bibliográfico sobre Ontologia;

- Identificação dos conceitos ontológicos, como: sujeito, predicado, objeto, classes, instâncias e propriedades de classes;

- Acompanhamento de tutoriais sobre o Protégé,

- Criação de quadros relacionais;

- Testes na ferramenta;

\footnotetext{
${ }^{8}$ A disciplina TEC1: Ontologia na Internet da FAC/UnB tem como objetivo proporcionar a complementação do conhecimento na área de ciência da computação para comunicação social, possibilitando a atualização e o aprofundamento em temas relacionados a estruturas da informação na Internet/Web. Propõem fornecer ao aluno as habilidades necessárias, do ponto de vista teórico e prático, para a construção de modelos baseados em ontologias, utilizados para a organização de comunicação, com base na recuperação da informação em um domínio do conhecimento. http://www.filosofiacienciaarte.org/index.php/curso-programacao-python/1068web-semântica

9 Destacam-se a colaboração de Hélio Santana (Estudante do Departamento de Ciência da Computação) e de Aimê Rivero (Estudante de Departamento de Filosofia).
} 
- Cadastramento das classes identificadas;

- Inserção dos predicados;

- Revisão dos relacionamentos entre classes e predicados;

- Cadastramento dos objetos;

- Inserção de instâncias; e

- Revisão dos relacionamentos;

A ontologia do Campus foi convertida em linguagem OWL (Web Ontology Language) pelo próprio Protégé, um software livre para edição de ontologia e que tem um framework com sistema de construção inteligente, na linguagem OWL. A linguagem OWL foi escolhida por ter mais dispositivos para expressar significado do que outras linguagens, como: XML, RDF, RDFS. Para a criação, foi utilizada a metodologia de desenvolvimento Ontology Development 101 em que são estabelecidas:

- Classes;

- Hierarquia de classes;

- Objetos;

- Hierarquia de objetos (predicados);

- Propriedades;

- Atributos de classe; e

- Instâncias ou indivíduos;

Para a construção da ontologia, foi necessário identificar e cadastrar o que são os sujeitos, predicados e os objetos (triplas da ontologia) que se relacionam no workflow do Campus. Entende-se como sujeito: as classes previamente cadastradas que fazem alguma ação, o predicado por sua vez são as ações que um sujeito exerce sobre um objeto e, para concluir a relação, os objetos são os que sofrem a ação. O Quadro 2 exemplifica algumas das relações mapeadas na criação da ontologia, em forma de triplas.

Quadro 2 - Triplas da Ontologia

\begin{tabular}{|l|l|l|}
\hline Sujeito & Predicado & Objeto \\
\hline Editores & Elaboram & Pré-pauta \\
\hline Editores & Aprovam & Matéria \\
\hline
\end{tabular}




\begin{tabular}{|l|l|l|}
\hline Editores & Reprovam & Matéria \\
\hline Conselho Editorial & Define & Plataforma \\
\hline Conselho Editorial & Discutem & Métricas \\
\hline Conselho Editorial & Define & Repórter \\
\hline Repórteres & Apuram & Solicitação de pauta \\
\hline Repórteres & Constroem & Matéria \\
\hline Repórteres & Efetuam & Entrevistas \\
\hline
\end{tabular}

Fonte: SILVA, 2019

$\mathrm{Na}$ Figura 5, Grafo da Ontologia do Campus

Fonte: SILVA, 2019, é possível visualizar um grafo da ontologia à direita, e as classes à esquerda no software Protégé. A figura mostra uma representação da ontologia a partir de um grafo, onde cada nó do grafo é representado pelas classes e cada linha demonstra as relações ou predicados. Vide APÊNDICE 5: Figura 5.

A ontologia construída tem diversos nós e ramificações (links) que podem ser aproximados e mais bem visualizados no programa. Os elementos representados em caixas são as classes, as linhas direcionais indicam as relações ou predicados para outras classes. No lado esquerdo da imagem, temos a representação de algumas classes e, no lado direito, as instâncias identificadas pelos losangos roxos. Ao analisarmos o grafo entendemos que algumas vantagens para se criar uma ontologia são:

- Compartilhar uma estrutura de informação entre pessoas ou agentes de software;

- Possibilitar a utilização do domínio de conhecimento;

- Tornar nítidas as hipóteses sobre o domínio;

- Separar o conhecimento do domínio e o conhecimento do conhecimento operacional;

- Analisar o domínio de conhecimento.

Ao retratar, no presente trabalho, o workflow do Campus, buscamos transmitir o conhecimento sobre o jornal de maneira estruturada, fornecer uma visualização mais ampla da redação, facilitar o planejamento para as novas turmas e dar continuidade às pesquisas sobre o jornal. Essa proposta foi possível com a validação do fluxo de trabalho pelo Conselho Editorial, o que fundamentou toda a pesquisa deste trabalho. 
Todo o trabalho foi orientado para tornar comum o conhecimento aplicado do Campus, permitir a reutilização do workflow e a transposição dos processos de linguagem natural para uma linguagem compreensível por máquinas e em sintonia com a estruturação de dados da Web Semântica.

Durante a construção da ontologia, verificaram-se dificuldades em descrever os processos decisórios e mapear todos os caminhos e alternativas, por exemplo, as razões e possibilidades que podem fazer com que uma pauta caia ou não. Diante dessa adversidade, percebemos que uma solução possível era a continuidade do trabalho, adaptando a modelagem de processo, e verificando se o software poderia incluir etapas sujeitas ao contexto de negócios. A decisão de descontinuidade de pauta ou não, seriam mais bem resolvidas se a edição do workflow fosse adaptável pelas próximas equipes do Campus de maneira mais prática.

\section{Gestão de Processos de Negócio (BPM) nas redações}

Não existe novidade em dizer que o Jornalismo está em crise, mas dizer que as TICs oferecem oportunidade requer mais explicações. O jornalismo é desafiado pela digitalização crescente dos processos e pela presença das mídias sociais, daí pode-se afirmar, que a redução do número de assinantes e a perda de receita dos anúncios, podem ser recuperadas pelo uso das TIC, desde que o seu uso ou aplicação aconteça em bases bem fundamentadas e uma transformação digital extremamente profissional, e esta é razão para dizer-se que as TIC oferecem oportunidades. As áreas de pesquisa, os desenvolvedores de softwares e os produtores de ferramentas podem atuar no suporte à produção de notícias, facilitar a exploração do mercado de comunicação em tempos de economia digital (BERVEN et al, 2020).

A produção de notícias como um processo de negócio faz todo o sentido, pois temos um conjunto de atividades interligadas que são executadas em ambiente organizacional, ou seja, a coordenação da produção da redação de um jornal, e que a cada dia passa a ser mais suportada por ferramentas e sistemas de informação mais adequados para alcançar o objetivo a que a gestão se propõe (TEIXEIRA JUNIOR, 2017).

Para citar tecnologias inovadoras que já estão atuando a serviço do jornalismo, tem- se: a Mineração de dados, a Inteligência Artificial, Aprendizagem de máquina (Machine Learning), e o Processamento de linguagem natural. Nesta seção tratar de mais uma destas áreas, a Gestão de Processos de Negócios (GPN). Ela é um bem estabelecido 
campo de pesquisa para Ciências da Computação, Sistemas de Informação e Administração, com largo uso nas grandes corporações.

\subsection{Tipos de processos}

Existem várias classificações para os processos de negócios de acordo com suas características e uma infinidade de notações ou Linguagens de Modelagem para processos operacionais (por exemplo, BPMN, Petri Nets, BPEL, YAWL, Álgebra de Processos, IDEF, UML e EPC). Os modelos podem ser matemáticos, gráficos, físicos, narrativos, ou algumas combinações destes tipos. $E$ as notações têm em comum que os processos são descritos em termos de atividades. Assim, uma prática é separar os processos em relação a suas estruturas e seus fluxos, logo é possível classificá-los como (FONSECA et al, 2018):

(i) Processos fortemente emoldurados ou estruturados (Totalmente previsível, altamente repetitivo);

(ii) Processos frouxamente emoldurados: Representa o comportamento do processo e um conjunto de restrições a priori, de modo que o modelo descreve a maneira padrão de se fazer as coisas;

(iii) Processos ad-hoc emoldurados: Não podem ser determinados em termos de lógica de processo explicito durante o tempo de modelagem, devido à falta de conhecimento de domínio ou a complexidade de combinações de tarefas.

(iv) Processos totalmente não-moldurados ou não estruturados: Totalmente imprevisível, altamente não repetitivo, e os participantes do processo precisam tomar decisões usando seus conhecimentos para criar atividades sob demanda.

\subsection{Linguagens de modelagem}

Na modelagem, as anotações e a análise de processos desempenham um papel central no gerenciamento de processos de negócios. Portanto, a escolha da linguagem de modelagem para representar os processos de uma organização é essencial. Existem algumas formas de dividir ou classificar as linguagens na literatura (TEIXEIRA JUNIOR, 2017). Aqui apresentam-se três classes de linguagens para facilitar sua caracterização ou identificação (FONSECA et al, 2018):

- Linguagens formais: Os processos são estudados usando modelos teóricos (matemáticos) 
- Linguagens conceituais: Têm rigorosa semântica e de baixo nível, e fornecem um valor aproximado do comportamento desejado;

- Linguagens de execução: Os processos de negócios especificados em BPEL são totalmente executáveis e portáveis entre ferramentas BPEL.

BPMN é uma linguagem gráfica e visa solucionar a comunicação empresarial por uma linguagem de notação intuitiva, através de processos complexos, considerado o padrão global para modelagem de processos pelo Object Management Group (OMG), em 2006.

O padrão de notação de Processos de Negócios BPMN fornece às empresas a capacidade de entender seus procedimentos comerciais internos em uma notação gráfica e dá às organizações a capacidade de comunicar estes procedimentos de forma padrão e mais clara. Isso permite que as organizações se ajustem rapidamente a novas circunstâncias comerciais internas, externa e business-to-business - B2B (FONSECA et al, 2018)

\subsection{Mapa BPM do Campus}

Uma organização de comunicação é conhecida como tendo um fluxo de informação, que aqui foi modelada como ontologia de domínio, e poderá ser também analisada como um mapa BPM (Business Process Management), e assim facilitar o atingimento dos seus objetivos. (NUNES et al, 2016). O BPM Businness Process Management tem sido aplicado em um grande número de organizações nas últimas décadas, geralmente, descrevendo um fluxo de controle de atividades bem estruturadas. A área de jornalismo não seria uma exceção, por exemplo, a produção da notícia pode ser modelada com ajuda de técnicas e software BPM.

O Jornal experimental da FAC/UnB foi modelado de maneira simples há cerca de 6 (seis) anos atrás (vide Figura 6 no APÊNDICE 6). Esta foi a primeira abordagem, e conseguiu-se representar um processo como um pequeno conjunto de atividades, e um pouco do seu comportamento. Tem-se um conjunto de restrições a priori, de modo que o modelo do processo descreva a "maneira padrão de se fazer as coisas". No entanto, a posteriori, um modelo requer adições, remoções ou geração de sequência de alternativas de atividades durante o tempo de execução.

Por outro lado, deve-se afirmar que os processos em uma redação jornalística são predominantemente do tipo ii, iii ou iv. No caso de um jornal experimental, para este estudo considera-se como um Processo frouxamente emoldurados, neste estudo. Vide Figura 7 (APÊNDICE 7) onde é possível construir uma modelagem bem mais próxima do 
mundo real. A elaboração do Mapa BPM do Campus foi o resultado de um trabalho colaborativo $^{10}$ de estudantes da disciplina Tópicos Especiais em Comunicação 1 Ontologia na Internet da FAC/UnB.

O modelo foi proposto com o intuito de descrever o processo de trabalho, que compreende as etapas de produção, apresentação, distribuição e análise do conteúdo. O modelo representado na Figura 7 foi desenvolvido na ferramenta de modelagem e gestão de processos Heflo ${ }^{11}$, ela é uma plataforma online, freemium, com utilização intuitiva e vastos recursos visuais. Vide APÊNDICE 7: Figura 7 - Grafo do mapa BPM do Campus (APÊNDICE 7) usando HEFLO ${ }^{12}$. Fonte: Trabalho colaborativo dos estudantes da Disciplina TEC1 - Ontologia na Internet (2019.

Não existe sempre um entendimento comum da gestão de um processo de negócio para os seus patrocinadores (professores) e participantes (estudantes). Portanto, é normal que eles guardem um gap entre suas perspectivas, da mesma forma que acontece entre os donos dos negócios e a visão da área de suporte de TI.

Com a abordagem convencional para modelagem com a elaboração do Mapa BPM do Campus, foi possível entender o processo como um fluxo de informações e ações, propor-se mudanças e aperfeiçoamento das atividades (Workflow) que a organização (Departamento de Jornalismo) possa realizar para alcançar seus objetivos, logo faz sentido desenvolver abordagem mais completa ou complexa caso julgue-se necessário.

Em estudos mais avançados, faz-se necessário oferecer suporte semântico ao jornalista para projetar processos sob demanda em uma redação jornalística flexível ${ }^{13}$. No entanto, sabe-se que nem todos os processos descritos são caracterizados como tendo os fluxos bem estruturados. Na vida real, existe a necessidade constante de atender demandas não previstas ou eventos não desejados que podem surgir no workflow. As situações não planejadas podem aparecer a qualquer momento durante a

\footnotetext{
${ }^{10}$ Os estudantes Aimê Rivero, Hélio Santana e Thallita Silva trabalharam na construção de um mapa BPM para o jornal Campus (2018).

${ }^{11}$ HEFLO é uma ferramenta de documentação de processos de negócio em que se editam os fluxos de processos online e. Os documentos são gerados automaticamente. https://www.heflo.com/pt-br/ferramenta-de-documentacao-de-processos-de-negocio/

12 HELFO é uma Plataforma para gerenciar negócios: http://hefol.com

${ }^{13}$ This research has been sponsored by Fundação de Apoio à Pesquisa do Distrito Federal (FAPDF), under the project "Flexible organizational information systems based on business processes with contextual semantic guidelines." Grant Number SEI 00193-00000096/2019-78. This case study of the project is part of the Experimental Laboratory for the Study of Digital Languages for Mobile Devices (Labdim) of the Department of Communication, University of Brasilia, registered under number 485707 at CNPq / 2013-6, in partnership with the Department of Computer Science (UnB) and Brunel University London, UK
} 
execução do processo, o que leva à necessidade de remodelação de forma a permitir tratar todos os caminhos, e chega-se a outro patamar, ou seja, o de processos flexíveis (NUNES et al, 2016).

\section{Considerações Finais e Perspectivas}

A modelagem do processo de produção de notícias do Jornal Campus da FAC/UnB demonstra a capacidade de se usar mapas mentais e conceituais para chegarse à ontologia do workflow do Campus. Os resultados foram alcançados e estão disponíveis para que o jornalista responsável e sua equipe de produção de notícias possam seguir o mesmo caminho aqui descrito, caso desejem. Como vantagens ele poderá entender e aperfeiçoar as etapas e ou todo o fluxo de informação de como um jornal universitário e experimental se comporta. Mas antes, devem ser considerados o contexto e as características do jornal em estudo, e proceder às adaptações necessárias no processo de modelagem.

Ao mapear o workflow do Campus, busca-se transmitir o conhecimento sobre o jornal de maneira estruturada, fornecer uma visualização mais ampla da redação, facilitar o planejamento para as novas turmas e dar continuidade às pesquisas sobre o jornal. Essa proposta foi possível com a validação do fluxo de trabalho pelo Conselho Editorial do Campus, medida que fundamentou toda a pesquisa deste trabalho.

\section{Aplicabilidade do experimento em outras redações:}

A modelagem ou a elaboração do workflow não representa uma aplicação trivial de uma ou mais ferramenta, pois ela é, antes de tudo, um método de trabalho de planejamento. A sua utilização por um profissional ou por uma equipe da área de jornalismo requer conhecimentos de mapas mentais e conceituais e ontologias. Assim, o caminho mais recomendado é a composição de um grupo interdisciplinar onde profissionais do jornalismo e da ciência da computação com experiência em Web Semântica trabalhem juntos. A ajuda de um professional com conhecimentos em ontologias, ou pela capacitação dos jornalistas, viabiliza o desenvolvimento e a capacidades de abstrair, a partir do modelo mental o processo produtivo das notícias e informações. Recomenda-se fazer um segundo caminho de modelagem que é a elaboração do Mapa BPM (Business Process Management).

Ao executar o estudo, seguindo a linha traçada da construção de modelos, aqui iniciando com um mapa mental, depois o mapa conceitual, e finalmente uma ontologia de domínio. A metodologia (Design Science Research - DSR) adotada pelos estudantes, 
pesquisadores e professores envolvidos foi o referencial que melhor atendeu, e deve atender outras aplicações. Todo o trabalho foi orientado para tornar comum $o$ conhecimento aplicado ao Campus, e permitir a reutilização do workflow em situações semelhantes ou a devida adaptação. No caso em tela iniciou pela a transposição dos processos de linguagem natural para uma linguagem compreensível por máquinas e em sintonia com a estruturação de dados da Web Semântica. Outros caminhos podem serem adotado, a depender da situação que grupo interdisciplinar encontrar.

Durante a construção da ontologia, verificamos a dificuldade em descrever os processos decisórios e mapear as razões que podem fazer com que uma pauta caia ou não, por exemplo. Nesse sentido, a construção do Mapa BPM (modelagem de processo de negócio) foi complementada com uma segunda modelagem. Logo, obteve-se dois retratos para o workflow do Campus. Deve-se, ainda, assinalar que isto é um o resultado de mais de 4 anos de trabalho cooperativo e colaborativo entre os departamentos de Jornalismo e Ciência da Computação da UnB, e nesta pesquisa foi uma assertiva de tomada de decisão.

\section{Perspectivas:}

O contexto das transformações digitais também cresce nas organizações e empresas de comunicação. Os modelos de gestão de negócios, que recenem vários nomes conceituais tais como jornalismo digital jornalismo de dados e cyberjornalismo, continuarão a crescer no ecossistema econômico e tecnológico. Assim, o campo da Comunicação parece ser um tema significativo para acadêmicos e profissionais quando estes tratam de seus objetos de pesquisa, preocupações e problemas dentro do contexto do ecossistema de informação contemporâneo (DOS SANTOS, 2021).

As redações virtuais têm asseguradas suas perspectivas na terceira década deste século, operando de forma distribuída, e seguirão pautando seus processos revendo o fluxo informação da produção, e tendo o jornalismo de dados como um processo a seguir. Estas mesmas redações contemporâneas adaptaram às novas formas de operar e produzir conteúdo. Os processos são fortalecidos com o uso das TIC, da checagem, para enfrentar as fakenews, ou seja, melhor coleta, da boa filtragem, do uso de ferramentas de construção e apresentação de conteúdos, até a distribuição em canais confiáveis. Ficando-se sempre alerta, à necessidade de medir os impactos e o valor das notícias, depois o engajamento em ambientes híbridos, adentrando no experimental e convergente mundo das mídias sociais (ISHIKAWA et al, 2021).

As perspectivas de continuarem as tensões entre priorizar e equilibrar a preferência dos leitores e o controle das notícias pelos jornalistas no processo de 
produção (workflow) são reais e úteis. O certo é que passa a ser uma luta entre a nova forma de produzir matérias jornalísticas mediadas pelas TIC, e o legado das práticas de hoje nas redações centralizadas. Isto tendo como cenário adverso os indicativos do mercado de publicidade e da sobrevivência do jornalismo (TSAKARRESTOU; POGKAS, 2017).

\section{Referências}

ALMEIDA, M; BAX, M. Uma visão geral sobre ontologias: pesquisa sobre definições, tipos, aplicações, métodos de avaliação e de construção. Revista Ciência da Informação. 32(3), 2003.

BARCELLOS, Zanei Ramos; GIL, Patrícia Guimarães. A Forma Flexível e Inclusiva de Fazer Jornalismo da Geração Z. Cadernos da Escola de Comunicação, v. 16, n. 1, p. 26-42, 2018.

BARCELLOS, Zanei; SILVA, Thallita Alves. Mapeamento do workflow do processo de produção de notícias multimídias para jornal digital Campus Multiplataforma. 2020. Disponível em:http://www.intercom.org.br/sis/eventos/2020/resumos/R15-05331.pdf Acesso em: 21 mar. 2021.

BERNERS-LEE; T.; HENDLER, J.; LASSILA, O. The Semantic Web. A new form of Web content that is meaningful to computers will unleash a revolution of new possibilities. 2001.

BERVEN, A.; CHRISTENSEN, O. A.; MOLDEKLEV, S., OPDAHL, A. L.; VILLANGER, K. J. A knowledge-graph platform for newsrooms. Computers in Industry, 123, 103321. 2020

BREITMAN, K. Web Semântica: a Internet do Futuro. Rio de Janeiro: Editora Eletrônica, 2005.

BUZAN, Tony. Mapa Mental. 2016.

DEUZE, M.; WITSCHGE, T. (2018). Beyond journalism: Theorizing the transformation of journalism. Journalism, 19(2), 165-181. 2018.

DE SOUSA, C. A. X.; BARCELLOS, Z. R. Aplicativos Jornalísticos | Universidade de Brasília, Brasília, DF. 2019. Intercom - Sociedade Brasileira de Estudos Interdisciplinares da Comunicação XXI Congresso de Ciências da Comunicação na Região Centro-Oeste - Goiânia - GO - 22 a 24/05/2019. Disponível em: https://portalintercom.org.br/anais/centrooeste2019/resumos/R66-0440-1.pdf

DOS SANTOS, M. C. Big Data and the Studies of Communication in Brazil -Notes on reconfiguring a knowledge field In: MEDEIROS NETO; LEAL; GHINEA (org). Digital Convergence in Contemporary Newsroom: Media Innovation, Content Adaptation, Device Mobility, and Cyber Journalism. Cidade: Editora: Springer, Berlin, Heidelberg. 2021.

FONSECA, M. B.; ISHIKAWA, E.; MEDEIROS NETO, B.; VICTORINO, M. Ferramenta para Anotação Semântica de Processos de Negócios de uma Redação Jornalística. ONTOBRÁS 2018, SP, p.239-244 http://ceur-ws.org/Vol-2228/.

ISHIKAWA, E; MEDEIROS NETO, B. Newsroom 3.1: Incorporations Social Media Management in Semantic Newsrooms with Flexible Business Process. In VIII Seminário Hispano-Brasileiro de Pesquisa em Informação, Documentação e Sociedade 2019. Escola do Futuro ECAIUSP - São Paulo - 11 à 14 de Novembro de 2019.

ISHIKAWA, E.; MEDEIROS NETO, B.; GHINEA, G. Perspectives of the Journalists Content Production from print newspaper to Virtual Newsroom 4.0 In: MEDEIROS NETO; LEAL; GHINEA (org). Digital Convergence in Contemporary Newsroom: Media 
Innovation, Content Adaptation, Device Mobility, and Cyber Journalism. Cidade: Editora: Springer, Berlin, Heidelberg. 2021.

JORGE, T. M.; MEDEIROS NETO, B. Journalistic Newsrooms: convergence and innovation on three continents. A case study on five media organizations. In: MEDEIROS NETO; LEAL; GHINEA (org). Digital Convergence in Contemporary Newsroom: Media Innovation, Content Adaptation, Device Mobility, and Cyber Journalism. Cidade: Editora: Springer (no prelo), Berlin, Heidelberg. 2021.

LAMMEL, luri; MIELNICZUK, Luciana. Aplicação da Web Semântica no jornalismo. Estudos Em Jornalismo e Mídia, v. 9, n. 1, p. 180-195, 2012.

MOLINA, Fernando; MEDEIROS NETO, Benedito. O perfil do jornalista 3.0: Novas competências necessárias para o jornalismo no século XXI. In Simpósio Internacional de Educação e Comunicação-SIMEDUC, n. 8, 2017.

NETO, B. M.; ISHIKAWA, E.; GHINEA, G., \& GRøNILO, T. M. (2019, January). Newsroom 3.0: Managing Technological and Media Convergence in Contemporary Newsrooms. In Proceedings of the 52nd Hawaii International Conference on System Sciences. 2019.

NUNES V.T., SANTORO F.M., WERNER C.M.L., RALHA C.G. (2016) Context and Planning for Dynamic Adaptation in PAIS. In: Reichert M., Reijers H. (eds) Business Process Management Workshops. BPM 2016. Lecture Notes in Business Information Processing, vol 256. Springer, Cham. https://doi.org/10.1007/978

SANTOS, É., MEDEIROS NETO, B., LENZI, A., \& Ghinea, G. Redações jornalísticas em contexto de convergência: um estudo comparativo exploratório no Brasil, na Costa Rica e na Inglaterra. Comunicação \& Inovação, 20(43). 2019.

SILVA, T. A. Workflow para auxiliar na modelagem de processos de produção de notícia em jornal laboratório. TCC apresentado à Faculdade de Comunicação da Universidade de Brasília, Brasília, DF. 2019.

TEIXEIRA JUNIOR, Gilmar et al. Modelagem de sistemas de informação para a mineração de processos: características e propriedades das linguagens. Universidade Federal de Goiás. 2017.

TRONCY, Raphaël. Bringing the IPTC news architecture into the semantic web. In: International Semantic Web Conference. Springer, Berlin, Heidelberg, 2008. p. 483-498.

TSAKARRESTOU, Betty; POGKAS, Demetrios. Data led newsrooms: Integration, collaboration and workflows in data first!media organizations. In For Future of Media and Communication Research: Media Ecology and Big Data International Conference N Fudan University, Shanghai, China. November, 2017. 
APÊNDICES - GRANDES FIGURAS

APÊNDICE 1: Figura 1 - Estruturação da Web Semântica

Fonte: Wikipédia - https://en.wikipedia.org/wiki/File:Semantic-web-stack.png

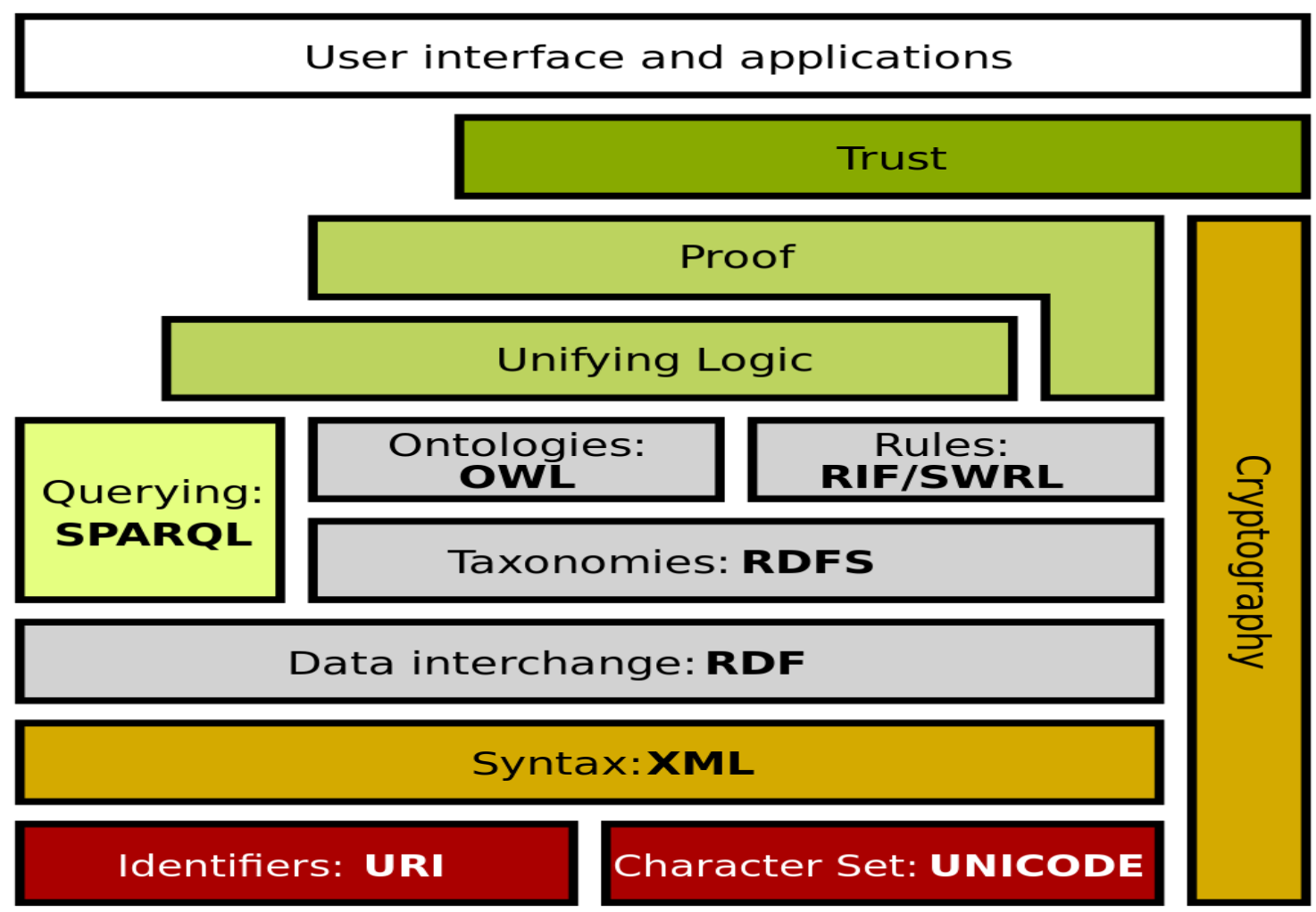


APÊNDICE 2: Figura 2 - Composição do Conselho Editorial 1/2019 (Mapa conceitual)

Fonte: SILVA, 2019, p.59

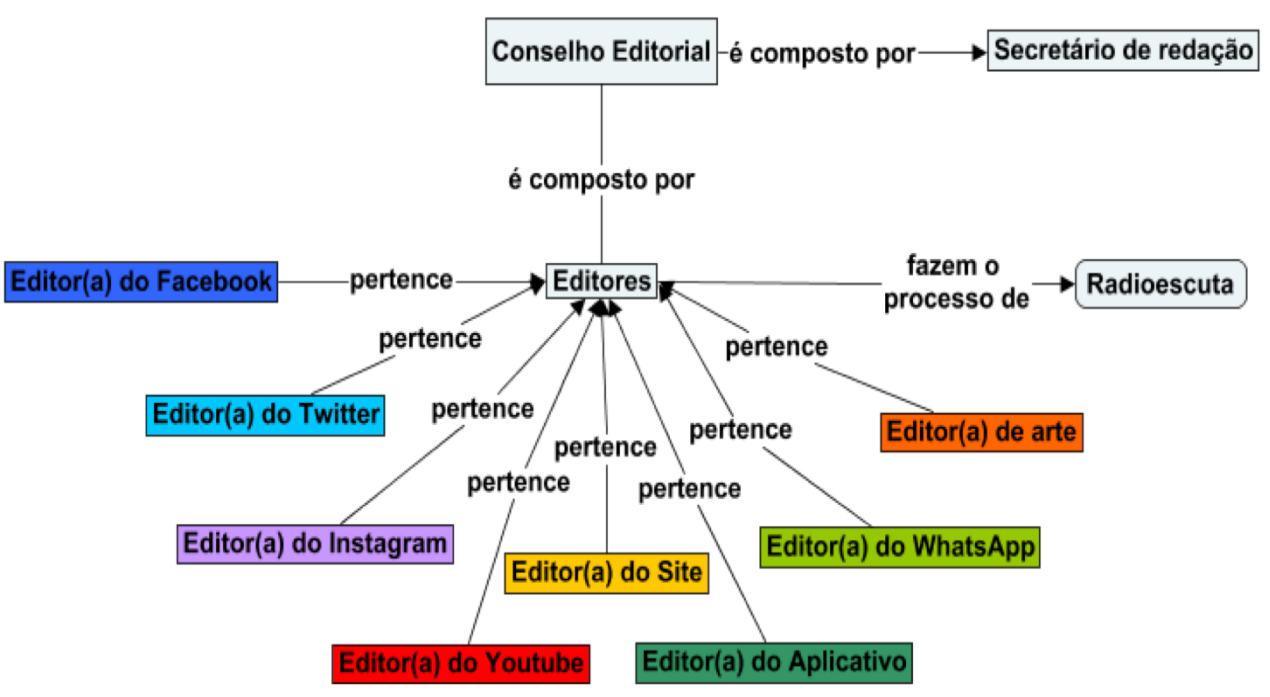


APÊNDICE 3: Figura 3 - Mapa mental em visualização cronológica. Fonte: SILVA, 2019.

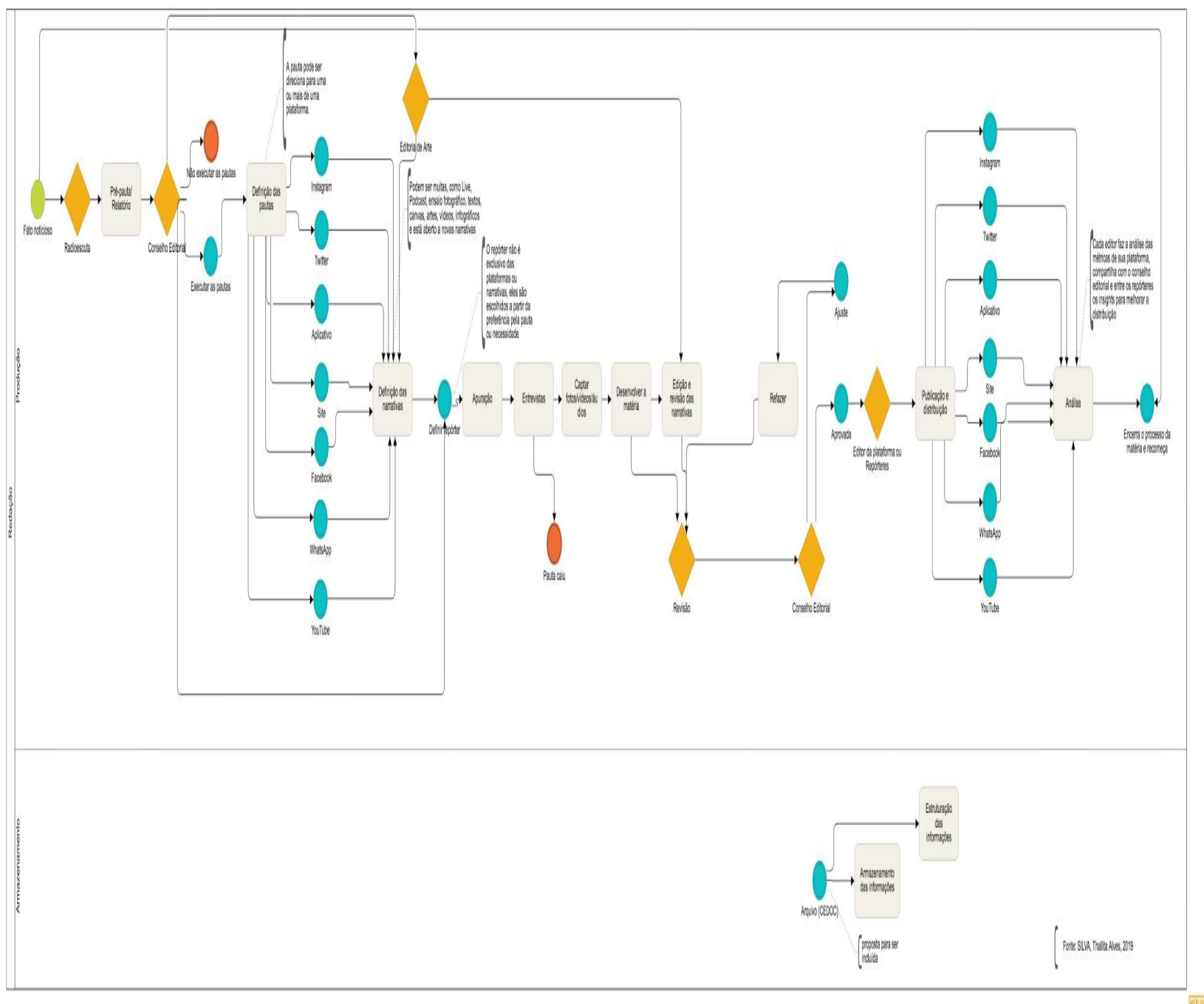


APÊNDICE 4: Figura 4 - Mapa Conceitual do Campus Multiplataforma. Fonte: SILVA, 2019, p.73.

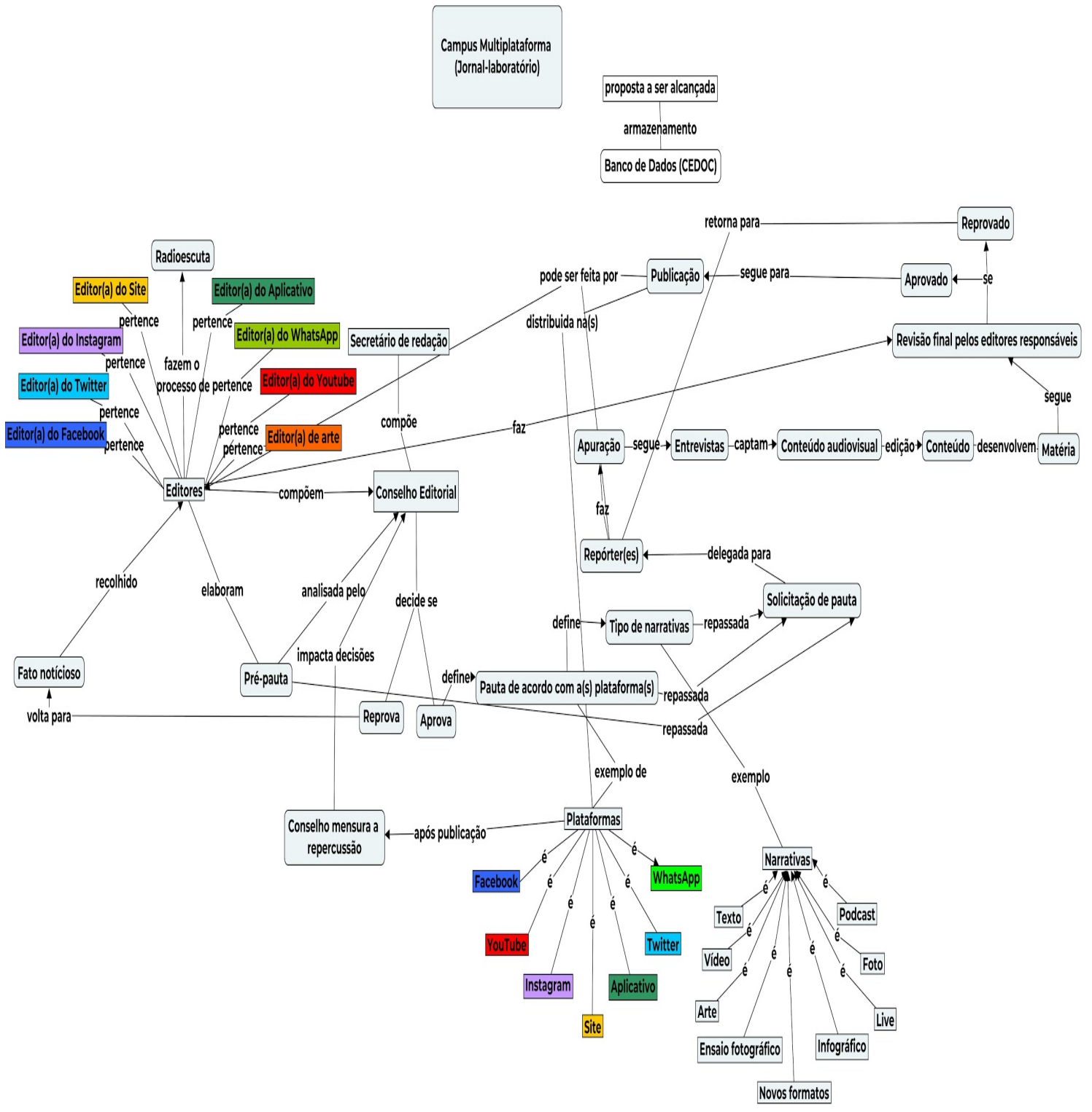


APÊNDICE 5: Figura 5 - Grafo da Ontologia do Campus. Fonte: SILVA, 2019.

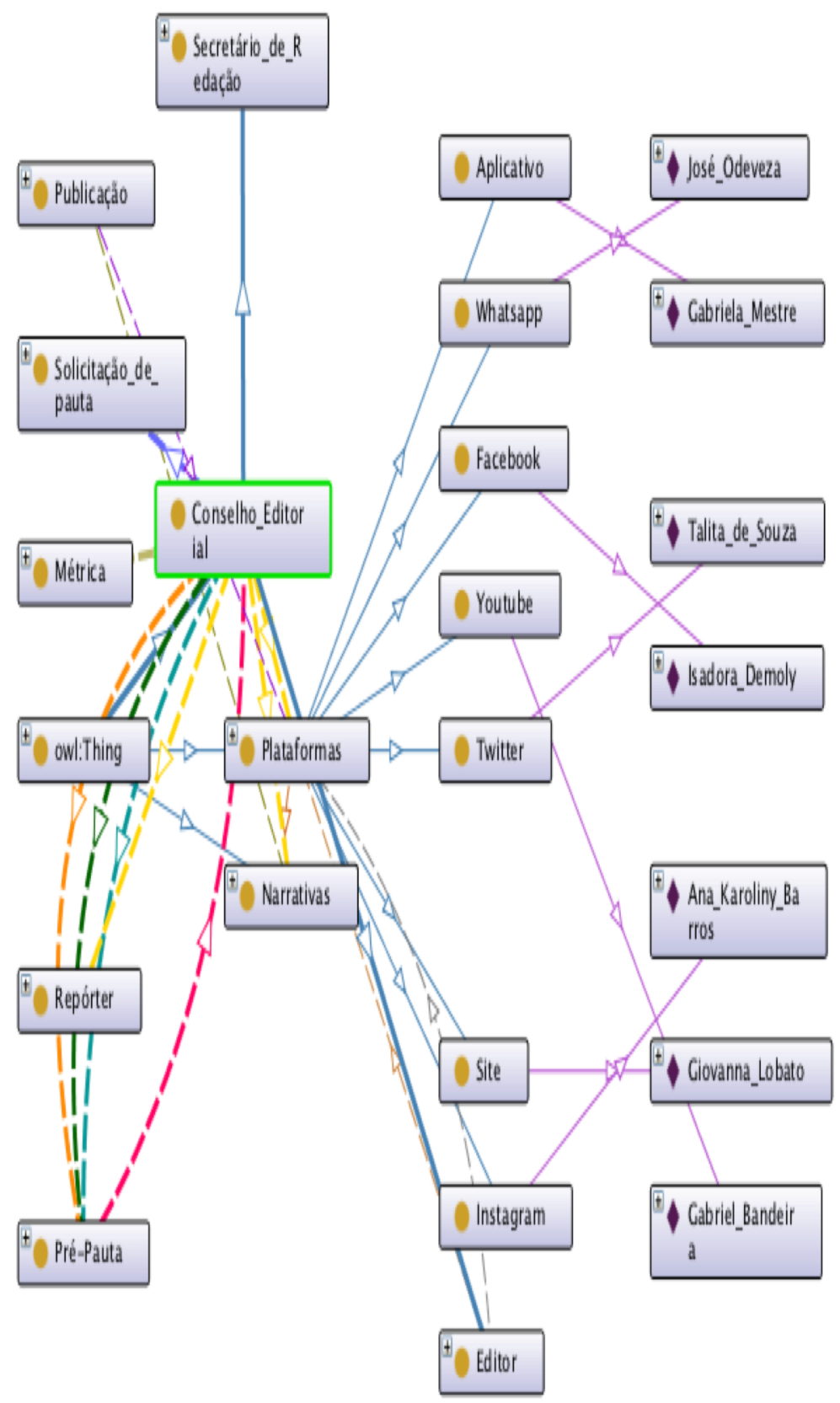


APÊNDICE 6: Figura 6 - Primeiro Mapa BPM do Campus usando Bizagit

Fonte: Trabalho colaborativos de estudantes da disciplina Jornalismo em Ambientes Digitais/FAC/UnB (2016)

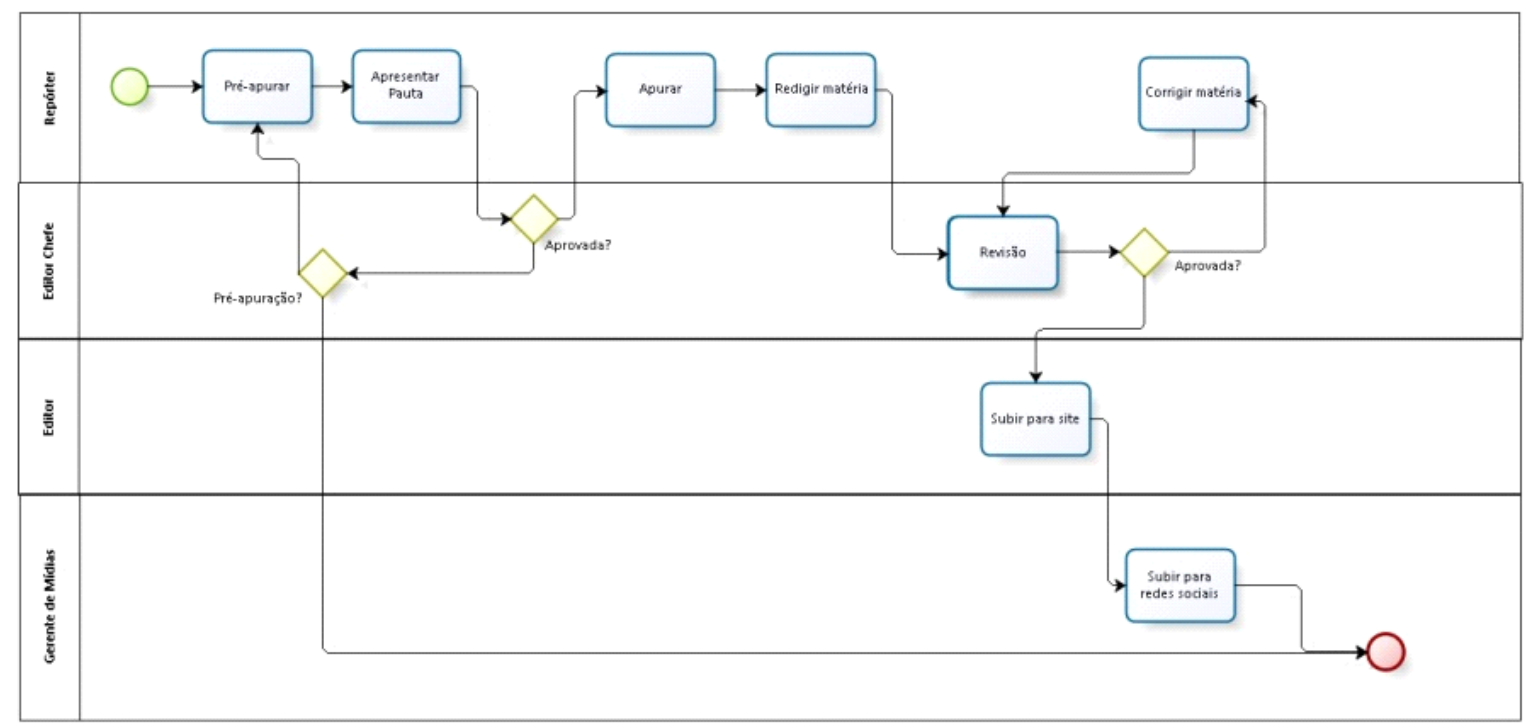

14 Bizagi é uma da linguagem de modelagem. Ela é composta de uma plataforma composta de três componentes. Cada componente facilita uma etapa fundamental na transformação e automatização dos seus processos: http://www.bizagi.com/pt/treinamento 
APÊNDICE 7: Figura 7 - Grafo do mapa BPM do Campus (APÊNDICE 7) usando HEFLO. Fonte: Trabalho colaborativo dos estudantes da Disciplina TEC1 - Ontologia na Internet (2019).

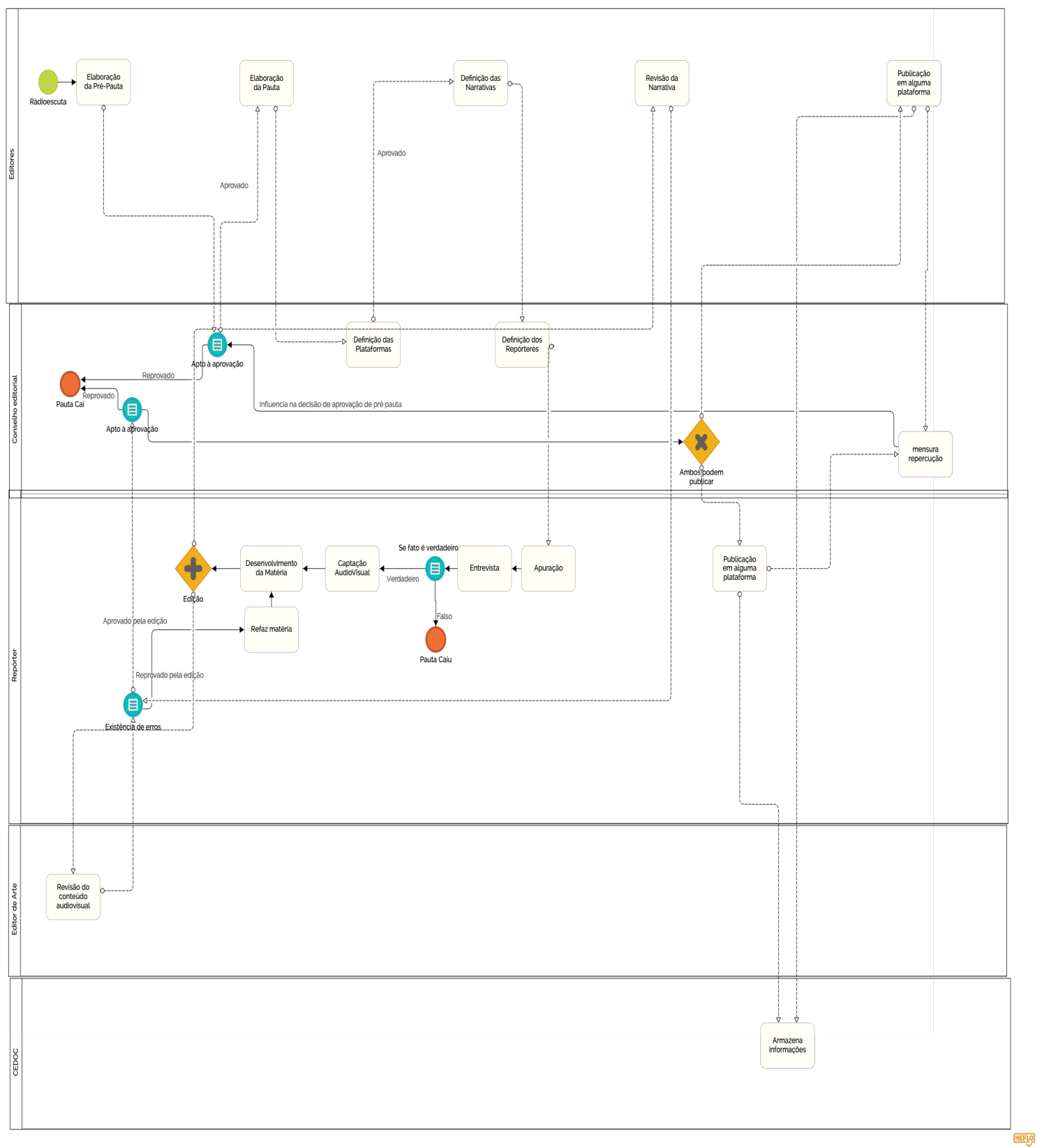




\section{arevisto Observatório}

ABSTRACT:

This research shows modeling based on mental and conceptual maps the workflow of a university journal and proposes a domain ontology. The study was carried out based on concepts such as multiplatform journalism, web journalism and the use of ICT. In methodological terms, it is a case study, combined with participant observation through semi-structured interviews. It was developed, as a part of the modeling, a mind map of the Campus Multiplataforma workflow. Then the process was improved to a concept map and finally the study arrived at a ontology. The results show the possibility of visually understanding the process of a newspaper, sharing or extrapolating it and applying it to other newsrooms, and also improving the workflow with the support of the process management map (BPM).

KEYWORDS: Workflow, Journalism multiplataform, experimental-journal, Mental map and conceptual map, Ontology.

\section{RESUMEN:}

Esta investigación muestra modelar el flujo de trabajo de un periódico universitario a partir de mapas mentales y conceptuales y propone una ontología de dominio. El estudio se realizó a partir de conceptos como periodismo multiplataforma, periodismo web y uso de las TIC. En términos metodológicos, se trata de un estudio de caso, combinado con la observación participante a través de entrevistas semiestructuradas. Como parte del modelado, se desarrolló un mapa mental del flujo de trabajo del Campus. Luego se mejoró el proceso a un mapa conceptual y finalmente se llegó a una ontología. Los resultados muestran la posibilidad de comprender visualmente el proceso de un periódico, compartirlo o extrapolarlo y aplicarlo a otras redacciones, y también mejorar el flujo de trabajo con el apoyo del mapa de gestión de procesos (BPM).

PALABRAS-CLAVES: flujo de trabajo; periodismo multiplataforma; periódico experimental; mapa mental y conceptual; ontología.. 